\title{
On the Relationship Between Dieting and "Obese" and Bulimic Eating Patterns
}

\author{
Tatjana van Strien \\ (Accepted 10 April 1995)
}

Objective: Relationships were studied between emotional, external and restrained eating behavior, and bulimia, and also between these types of eating behavior and body dissatisfaction and drive for thinness. Method: The sample consisted of female adolescents. Eating behavior and body evaluation were measured with scales of the Dutch Eating Behaviour Questionnaire (DEBQ) and the Eating Disorders Inventory (EDI). Results: Significant and high relationships were found between emotional and external and bulimic eating behavior. The same was true for restrained eating, and body dissatisfaction and drive for thinness. However, results from factor analyses suggest that the three types of overeating do not point to one and the same construct. Further, also restrained eating was found to point at a different construct than the construct associated with body dissatisfaction and drive for thinness. Finally, no high relationships were found between restrained eating and "obese" or bulimic eating patterns. Discussion. The low relationship between restrained eating and various types of overeating is in line with earlier results with the DEBQ Restraint scale and offers further support for the contention that the excessive food intake found in subjects with high scores on the Herman and Polivy's Restraint Scale (RS) may be an artefact of the RS, as a result of its bias towards the selection of a counterregulating sample (C) 1996 by John Wiley \& Sons, Inc.

In a series of laboratory experiments into factors responsible for overeating, it was found that subjects scoring high on the Restraint Scale (RS; Herman, Polivy, Pliner, Threlkeld, \& Munic, 1978), which is intended to be a self-report measure of dietary restraint, showed excessive food intake when their self-control was undermined by so-called disinhibitors of restraint. When subjects ate a preload excessive in energy (Herman \& Mack, 1975), when they believe the preload had high caloric content (Polivy, 1976; Spencer \& Fremouw, 1979; Woody, Costanzo, Liefer, \& Conger, 1981), when depression

Tatjana van Strien, Ph.D., is a staff member at the Department of Clinical Psychology and Personality Psychology at the University of Nijmegen. She is also affiliated with UNRAB, the University of Nijmegen research group on Addictive Behaviours. Address reprint requests to her at Vakgroep Klinische psychologie en Persoonlijkheidsleer, Katholieke Universiteit Nijmegen, Postbus 9104, Nijmegen, The Netherlands. 
or anxiety was induced (Baucom \& Aiken, 1981; Frost, Goolkasian, Ely \& Blanchard, 1982; Herman \& Polivy, 1975; Polivy \& Herman, 1976a; Ruderman, 1985), or when alcohol was administered (Polivy \& Herman, 1976b), those high on restraint exhibited excessive food intake. These outcomes have resulted in the formulation of so called restraint theory, which posits a causal role for dietary restraint in the development of overeating (Herman \& Polivy, 1980). Further, these findings are regarded as an experimental analog of binge eating (Wardle \& Beinart, 1981) as clinical reports of patients with bulimia nervosa indicate that an episode of dieting often preceded the onset of their eating disorder (Boskind-Lodahl, 1976; Bruch, 1973).

It has been noted (Wardle et al., 1992, p. 168) that the disinhibitors in restraint theory have high similarity to the cues for overeating central in psychosomatic and externality theory thought to be characteristic for the obese, that is, eating in response to negative emotions (emotional eating) and eating in response to food-related stimuli (external eating). In contrast to restraint theory, however, in psychosomatic and externality theory these "obese" eating patterns are thought to precede dieting (Slochower, 1983; Rodin, 1980). Furthermore, an association has been made between emotional and external eating behavior and the bulimic attacks of patients with anorexia and bulimia nervosa (Wardle, 1987). Approximately $50 \%$ of patients with anorexia nervosa, in which selfimposed starvation is a central feature, also have bulimic attacks. These bulimic attacks are also marked by excessive eating under conditions of emotional stress or when food cues are present (Abraham \& Beumont, 1982).

Although there may be a face resemblance between the "obese" eating patterns of emotional and external eating behavior, and bulimic eating behavior, the actual interrelations between these patterns of overeating remain to be assessed. Additionally, the determination of the relationship between dieting and various patterns of overeating continues to be of interest as the typical counterregulatory eating behavior of the Herman and Polivy restrained eater failed to emerge in subjects classified as restrained eater by other measures of restraint: The restraint scales of the Dutch Eating Behavior Questionnaire (DEBQ; Van Strien, Frijters, Bergers, \& Defares, 1986) and of the Three Factor Eating Questionnaire (TFEQ; Stunkard \& Messick, 1985; Jansen, Oosterlaan, Merckelbach, \& Van den Hout, 1988; Wardle \& Beales, 1987; Lowe \& Kleifield, 1988). The DEBQ and TFEQ restraint scales measure intentions to restrict food intake and actual control of food intake (Van Strien, Frijters, Van Staveren, Defares, \& Deurenberg, 1986; Wardle \& Beales, 1987; Hill \& Robinson, 1991; Laessle, Tuschl, Kotthaus, \& Pirke, 1989; Wardle et al., 1992). In this they contrast with the Herman and Polivy RS, which may be biased towards the selection of a counterregulating sample as in addition to items reflecting food restriction, it also contains items indicating disinhibition of control over eating (Stunkard \& Messick, 1985; Van Strien, 1986, p. 125; Wardle, 1987; Charnock, 1989). If the present study does not find a relationship between restrained eating, as operationalized by a scale measuring intention or actual control of food intake and patterns of overeating, this would indicate support for the contention that the typical counterregulatory or disinhibitive food intake shown by the Herman and Polivy restrained eater is not related to restraint per se but to disinhibition of restraint.

This study investigated the relationships between emotional, external and restraint eating behavior, and bulimia, as operationalized by scales of the DEBQ and the Eating Disorders Inventory (EDI; Garner, Olmsted, \& Polivy, 1983). The following three hypotheses have been formulated. Firstly, in line with both theory (Slochower, 1983; Schachter \& Rodin, 1974) and earlier findings (Van Strien, Schippers, \& Cox, in press), it is expected that emotional and external eating behavior are significantly interrelated, 
yet can be shown to refer to independent constructs. Secondly, in line with the contention of, for example, Wardle (1987), significant and high relationships are expected between both types of eating behavior and bulimia, but left as an open empirical question is whether bulimia and emotional and/or external eating behavior point at one and the same construct. Thirdly, because opposing hypotheses can be formulated, it is also left as an open empirical question whether a relationship will be found between restrained eating and the various patterns of overeating. Other variables in this study represent body evaluation and psychological aspects considered relevant for disordered eating, as measured by the remaining scales of the EDI.

Due to sex differences in the prevalence of disordered eating patterns, an exclusively female sample of grammar school students was chosen for the study.

\section{METHOD}

\section{Subjects}

Subjects were 735 adolescent girls with a mean age of 15.6 years $(S D=1.5)$, who attended six different schools in the eastern part of the Netherlands ranging from lower vocational to pre-university education. In addition to demographic questions and general questions on health and eating behavior, the questionnaire also contained scales specific for the early recognition and assessment of eating disorders. It was administered under supervision of one of the school teachers as well as the researcher. Permission to participate in the study on health and eating behavior was obtained from the parents of the students. Ninety-six percent of the students returned the questionnaires, but as time limits were imposed (subjects had to complete the questionnaire during the course of one lesson) only 481 questionnaires were fully completed.

\section{Instruments}

For the present study only the DEBQ and EDI in the general questionnaire are of relevance. The DEBQ contains 33 items forming three scales. Ten items are on restrained eating (do you try to eat less at mealtimes than you would like to eat?). Ten items are on external eating (if you walk past the bakery do you have the desire to buy something delicious?). ${ }^{*}$ Finally, 13 items are on emotional eating (do you have a desire to eat when you are irritated?). Each of the three scales has been shown to have good internal consistency and factorial validity (Van Strien, Frijters, Bergers et al., 1986; Wardle, 1987). All items have a five-option response format: never (1), seldom (2), sometimes (3), often (4), and very often (5). Some items also have a "not relevant" response option, which are treated as missing data in the present study (Van Strien, Frijters, Bergers et al., 1986). Scores for each scale are obtained by dividing the sum of the item endorsements by the total number of items endorsed. A high score indicates a high degree of the eating behavior in question.

\footnotetext{
* In the present study one item had to be deleted due to a typing error. Thus the scale on external eating behavior contains only nine items in the present study.
} 
The EDI (Garner et al., 1983) contains 64 items and consists of eight subscales: Body Dissatisfaction (BD), Drive for Thinness (DT), Bulimia (BU), Ineffectiveness (I), Perfectionism (P), Interpersonal Distrust (ID), Interoceptive Awareness (IA), and Maturity Fears (MF). The EDI was translated into Dutch (Schoemaker, van Strien, \& Van der Staak, 1994). All items have a six-option response format: never (1), rarely (2), sometimes (3), often (4), usually (5), and always (6). In contrast with the EDI manual (Garner, 1990) in which a transformation to responses into a 4-point scale is advocated, untransformed responses were used in the present study, as scale transformation was found to damage the sensitivity and validity of the EDI in a nonclinical population (Schoemaker et al., 1994).

\section{RESULTS}

To determine the interrelations between scores on the scales of the DEBQ and those of the EDI, Pearson product-moment correlation coefficients were computed between the three DEBQ scales and the eight EDI scales. These coefficients, along with the means, standard deviations, and Cronbach's alphas of the scales, are presented in Table 1.

As could be expected from other studies (e.g., Van Strien et al., in press), emotional eating was found to be positively related to external eating. Additionally, both types of eating behavior were positively and significantly related to the EDI Bulimia scale. In contrast, the correlations between the DEBQ restraint scale on the one hand, and the DEBQ emotional and external eating scales and the EDI BU scale on the other hand, were, even when significant, on the low side (below .30). However, significant and high correlations were found between the DEBQ restraint scale and the EDI scales BD and DT. Additionally, correlations between the three DEBQ scales and the other scales of the EDI were, although in most cases significant, generally low (below .30). Finally, as in the study of Garner et al. (1982), most EDI subscales were significantly intercorrelated, although the correlation coefficients were generally low (only three were above .50).

As the results obtained with the EDI scales pertaining to the psychological aspects of disordered eating were disappointing, in further analyses the exploration of the construct validity was restricted to the DEBQ and EDI scales pertaining to eating behavior and body evaluation. Specifically, the construct validity was explored on the level of the items of these scales. Various orthogonal rotated factor analyses (varimax) were conducted on the 55 items of all three DEBQ scales and the EDI scales BU, BD, and DT. The four-factor solution, which was also in accordance with the elbow of the eigenplot, provided the most stable solution across the samples, as the factor structure obtained in the entire sample was more or less identical to the one obtained in a subsample of 192 students who had indicated they had problems with overeating. + Table 2 shows the results of the first two factors of this solution obtained in the entire sample, showing item loadings higher than .40. The third and fourth factors are not shown, as the third factor, accounting for $5.8 \%$ of the variance, was formed by all items of the DEBQre-

+ These subjects had given an affirmative answer to the question: Have you ever had an eating binge, for example, have you ever eaten an amount of food that others would consider unusually large? (yes/no). 


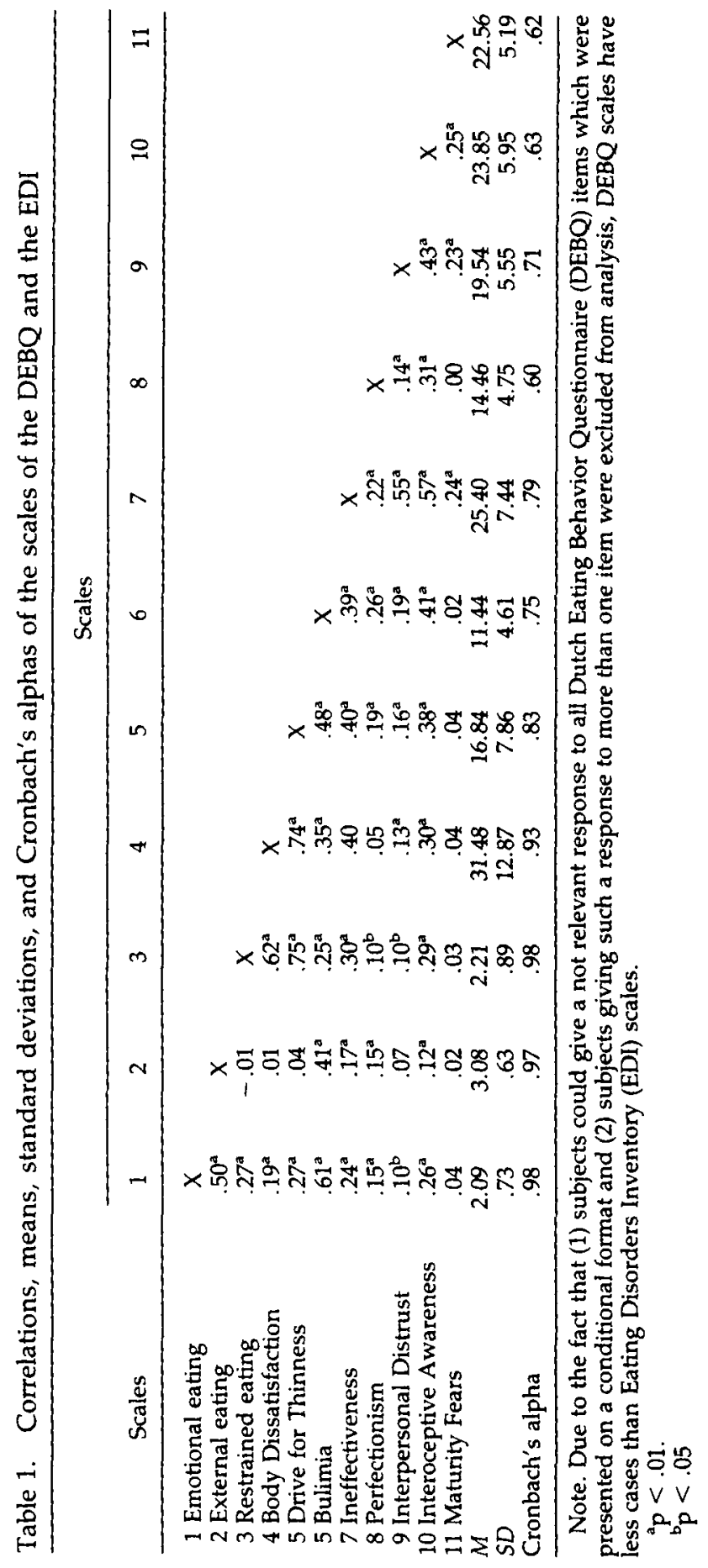


Table 2. Factor loadings of the items of the EDI scales: Bulimia, Body Dissatisfaction, and Drive for Thinness and the DEBQ scales: emotional, external, and restrained eating behavior

\begin{tabular}{|c|c|c|c|}
\hline & & \multicolumn{2}{|c|}{ Factor Loadings ${ }^{a}$} \\
\hline & & Factor 1 & Factor 2 \\
\hline \multicolumn{4}{|c|}{ EDI Bulimia scale } \\
\hline 4 & I eat when I am upset & & 52 \\
\hline 5 & I stuff myself with food & 41 & 45 \\
\hline 28 & I have gone on eating binges where I felt that I could not stop & & 43 \\
\hline 38 & I think about binging (overeating) & & 44 \\
\hline 46 & I eat moderately in front of others and stuff myself when they are gone & 48 & \\
\hline 53 & I have the thought of trying to vomit in order to lose weight & 42 & \\
\hline 61 & I eat or drink in secrecy & & \\
\hline \multicolumn{4}{|c|}{ EDI Body Dissatisfaction } \\
\hline 2 & I think that my stomach is too big & 72 & \\
\hline 9 & I think that my thighs are too large & 78 & \\
\hline 12 & I think that my stomach is just the right size $\mathrm{e}^{\mathrm{b}}$ & 69 & \\
\hline 19 & I feel satisfied with the shape of my body ${ }^{b}$ & 74 & \\
\hline 31 & I like the shape of my buttocks ${ }^{b}$ & 70 & \\
\hline 45 & I think my hips are too big & 76 & \\
\hline 55 & I think that my thighs are just the right size ${ }^{b}$ & 76 & \\
\hline 59 & I think my buttocks are too large & 77 & \\
\hline 62 & I think that my hips are just the right size ${ }^{b}$ & 73 & \\
\hline \multicolumn{4}{|c|}{ EDI Drive for Thinness } \\
\hline 1 & I eat sweets and carbohydrates without feeling nervous & & \\
\hline 7 & I think about dieting & 76 & \\
\hline 11 & I feel extremely guilty after overating & 55 & \\
\hline 16 & I am terrified of gaining weight & 68 & \\
\hline 25 & I exaggerate or magnify the importance of weight & 63 & \\
\hline 32 & I am preoccupied with the desire to be thinner & 76 & \\
\hline 49 & If I gain a pound, I worry that I will keep gaining & 58 & \\
\hline \multicolumn{4}{|c|}{ DEBQ Emotional Eating } \\
\hline 1 & Do you have the desire to eat when you are irritated?c & & 68 \\
\hline 3 & Do you have a desire to eat when you have nothing to do? & & 50 \\
\hline 5 & Do you have a desire to eat when you are depressed or discouraged? ${ }^{c}$ & & 69 \\
\hline 8 & Do you have a desire to eat when you are feeling lonely? & & 55 \\
\hline 10 & Do you have a desire to eat when somebody lets you down? ${ }^{b}$ & & 66 \\
\hline 13 & Do you have a desire to eat when you are cross? ${ }^{c}$ & & 71 \\
\hline \multirow[t]{2}{*}{16} & Do you have a desire to eat when you are approaching & & \\
\hline & something unpleasant to happen/c & & 64 \\
\hline 20 & Do you have a desire to eat when you are anxious, worried, or tense? ${ }^{c}$ & & 73 \\
\hline \multirow[t]{2}{*}{23} & Do you have a desire to eat when things are going against you & & \\
\hline & or when things have gone wrong? & & 74 \\
\hline 25 & Do you have a desire to eat when you are emotionally upset? ${ }^{c}$ & & 53 \\
\hline 28 & Do you have a desire to eat when you are bored or restless? & & 65 \\
\hline 30 & Do you have a desire to eat when you are frightened? ${ }^{c}$ & & 64 \\
\hline 32 & Do you have a desire to eat when you are disappointed? ${ }^{c}$ & & 75 \\
\hline$\%$ & Variance & 25.8 & 13.4 \\
\hline
\end{tabular}

${ }^{a}$ All decimal points are omitted. Only loadings higher than .40 are presented.

bIndicates negatively keyed items.

ltems with a nonrelevant response category.

strained scale. The fourth factor, accounting for $4.1 \%$ of the variance, was formed by all but one item of the DEBQ external eating scale. $\neq$

As can be seen in Table 2, the EDI BU scale comprised two dimensions. One part of the items, for example, "I eat moderately in front of others and stuff myself when they

The complete table, including the results obtained from the subpopulation of women having problems with overeating, can be obtained from the author. 
are gone" and "I have the thought of trying to vomit in order to lose weight," in short, items pertaining to eating in private or to vomiting, loaded on the first factor. Remarkably, this dimension also consisted of items pertaining to dissatisfaction with figure and drive for thinness. The other part, for example, "I stuff myself with food," "I think about binging (overeating)," "I have gone on eating binges where I have felt that I could not stop," and "I eat when I am upset," in short items pertaining to overeating or binging, impetus unspecified, loaded on the second factor. This dimension also featured all items on emotional eating.

\section{DISCUSSION}

Emotional eating was found to be significantly related to external eating. This is in line with both theory (Slochower, 1983; Schachter \& Rodin, 1974) and earlier findings (Van Strien et al., in press). Additionally, both types of eating behavior were found to be significantly and highly related to bulimia. In spite of this, however, the three types of overeating do not seem to point at one and the same construct. Inspection of the factor loadings of the items on which the measures of emotional, external, and bulimic behavior are based revealed that the EDI BU scale comprised two dimensions. One part of the items loaded on a dimension that also consisted of items pertaining to dissatisfaction with figure and drive for thinness. The other part loaded on a dimension that also featured items on emotional eating. The latter finding implicates that emotional and bulimic eating behavior, at least as operationalized by the DEBQ and EDI, only partly point at one and the same construct. A further outcome of the factor analyses was that the items pertaining to external eating all loaded on a separate dimension. This implies that external eating points at a construct that differs from either emotional or bulimic eating behavior.

The relationship between "obese" eating patterns and restrained eating was not found to be very impressive. The same was true for the relationship between bulimia and restrained eating. In contrast, significant and high relationships were found between restrained eating, and body dissatisfaction and a drive for thinness. However, in factor analyses items on restrained eating all loaded on a separate factor. This indicates that restrained eating points at a construct that not only differs from bulimic or obese eating patterns, but also differs from body dissatisfaction and the drive for thinness.

Similar results were found by Laessle et al. (1989). In a factor analysis on the scale scores of restraint scales and related measures, the DEBQ restraint scale did not constitute a common factor with scales representing counterregulation or disinhibited eating or body dissatisfaction, and only a weak relationship was found with the drive for thinness. Furthermore, the DEBQ restraint scale also did not constitute a common factor with the Herman and Polivy RS, which could lead one to interpret that these two measures of restraint measure different constructs.

The low association between the DEBQ restraint scale and different aspects of overeating found in the present study is also in line with the finding that subjects with high scores on the DEBQ restraint scale did not exhibit preload or affect induced overeating in the laboratory (Jansen et al., 1988; Wardle \& Beales, 1987), and that manipulation of perceived hunger and satiety had no effect on their subsequent eating (Ogden \& Wardle, 1990). These findings also are in line with findings obtained utilizing the highly similar restraint scale of the TFEQ (Lowe, 1993, p. 103).

The present finding that relationships between restrained eating, as measured by the DEBQ restraint scale, and the various forms of overeating were not impressive offers 
support for the contention that the excessive food intake found in subjects scoring high on the Herman and Polivy RS (RS) may be an artefact of the RS, as a result of its bias towards the selection of a counterregulating sample. The RS probably measures disinhibition instead of pure restraint. For restraint theory this means that not all dieters, but only a subpopulation with a tendency towards disinhibition, show excessive food intake when coming off a diet.

Another point that needs to be addressed here is that it remains to be proven that the disinhibition of restraint displayed by some restrained eaters is "a direct consequence of their restraint" (Heatherton, Herman, Polivy, King, \& McGree, 1988, p. 20). Indeed, the well-documented inability of many dieters to achieve and maintain weight loss and their disinhibitive properties do not constitute any evidence whatsoever that restraint causes disinhibition. If a tendency to binge is not found in all dieters but only in a subpopulation having a tendency towards disinhibition, may it not be equally assumed that this tendency precedes dieting rather than is resulting from dieting? In other words, and this is exactly the position of psychosomatic and externality theory: A tendency to overeat under certain conditions may cause weight problems and make dieting necessary§ (see also Lowe, 1993, p. 112).

However, this interpretation goes beyond the scope of the present study, as causal conclusions cannot be drawn due to the correlational nature of the data in this crosssectional study. Nevertheless, a first step in answering this complex question may be to distinguish between successful and unsuccessful dieters (Ogden \& Wardle, 1991; Westenhoefer, 1991).

Although the DEBQ restraint scale was intended to measure dieting and was found to have good predictive validity for the restriction of food intake (Van Strien, Frijters, Van Staveren, et al., 1986; Wardle \& Beales, 1987; Hill \& Robinson, 1991; Wardle et al., 1992), not all subjects with high scores on this scale are "exclusively restrained" (Ogden, 1993). Some may also have a tendency towards disinhibition, as can be inferred from the significant (but low) associations between scores on the DEBQ restraint scale and scores on the DEBQ emotional and external eating scale as well as the EDI BU scale. One means to distinguish the successful dieters from those who have tendency to break their restraint, may be to analyze the results in relationship to the tendency to overeat or to binge. The DEBQ scales of emotional and external eating behavior seem to be appropriate tools in identifying subjects at risk for overeating, in addition to the EDI BU scale for measurement of binge eating tendencies.

The two dimensionality of the EDI BU scale needs further clarification, however. Additionaly, present results utilizing the EDI scales pertaining to psychological aspects of disordered eating were rather disappointing, and that their specificity for eating disorders remains to be proven (e.g., Cooper, Cooper, \& Fairburn, 1985).

\section{REFERENCES}

Abraham, S. F., \& Beumont, P. J. V. (1982). How patients describe bulimia or binge eating. Psychological Medicine, 12, 625-635.

$\$$ This point of view does not preclude that behavioral and metabolic side effects of dieting may lead to further disruption of intake regulation, and by doing so ameliorate problems with eating behavior and weight regulation, turning the eating behavior problem into an eating disorder. 
Baucom, D. H., \& Aiken, P. A. (1981). Effect of depressed mood on eating among obese and nonobese dieting and nondieting persons. Journal of Personality and Social Psychology, 41, 577-585.

Boskind-Lodahl, M. (1976). Cinderella's stepsisters: A feminist perspective on anorexia nervosa and bulimia. Signs: A Journal of Women in Culture and Society, 2, 342-352.

Bruch, H. (1973). Eating disorders. New York: Basic Books.

Charnock, D. J. K. (1989). A comment on the role of dietary restraint in the development of bulimia nervosa. British Journal of Clinical Psychology. 28, 329-340.

Cooper, Z., Cooper, P. J., \& Fairburn, C. G. (1985). The specifity of the Eating Disorder Inventory. British Journal of Clinical Psychology, 24, 129-130.

Frost, R. O., Goolkasian, G. A., Ely, R. J., \& Blanchard, F. A. (1982). Depression, restraint and eating behaviour. Behaviour Research and Therapy, 20, 113-121.

Garner, D. M. (1990). Eating Disorder Inventory-2. Professional manual. Odessa, FL: Psychological Assessment Resources.

Garner, D. M., Olmstead, M. A. \& Polivy, J. (1983). Development and validation of a multidimensional eating disorder inventory for anorexia nervosa and bulimia. International Journal of Eating Disorders, 2, 15-34.

Heatherton, T. F., Herman, C. P., Polivy, J., King, G. A., \& McGree, S. T. (1988). The (mis)measurement of restraint: An analysis of conceptual and psychometric issues. Journal of Abnormal Psychology, 97, 19-28.

Herman, C. P., \& Mack, D. (1975). Restrained and unrestrained eating behaviour. Journal of Personality, 43, 647-660.

Herman, C. P., \& Polivy, J. (1975). Anxiety, restraint and eating behavior. Journal of Abnormal Psychology, 84, $666-672$.

Herman, C. P., \& Polivy, J. (1980). Restrained eating. In A. J. Stunkard (Ed.), Obesity pp. 208-225). Philadelphia: W.B. Saunders.

Herman, C. P., Polivy, J., Pliner, P., Threlheld, J., \& Munic, D. (1978). Distractability in dieters and nondieters: An alternative viewed "externality". Journal of Personality and Social Psychology, 36, 536-548.

Hill, A. J., \& Robinson, A. (1991). Dieting concerns have a functional effect on the behaviour of nine-year-old girls. British Journal of Clinical Psychology, 30, 265-267.

Jansen, A., Oosterlaan, J., Merckelbach, H., \& Van den Hout, M. (1988). Nonregulation of food intake in restrained, emotional and external eaters. Journal of Psychopathology and Behavioral Assessment, 10, 345-353.

Laessle, R. G., Tuschl, R. J., Kotthaus, B. C., \& Pirke, K. M. (1989). A comparison of the validity of three scales for the assessment of dietary restraint. Journal of Abnormal Psychology, 98, 504-507.

Lowe, M. R. (1993). The effects of dieting on eating behaviour: A three-factor model. Psychological Bulletin, 114, 100-121.

Lowe, M. R., \& Kleifield, E. (1988). Cognitive restraint, weight suppression, and the regulation of eating. Appetite, 10, 159-168.

Ogden, J. (1993). The measurement of restraint: Confounding success and failure? International Journal of Eating Disorders, 13, 69-76.

Ogden, J., \& Wardle, J. (1990). Cognitive restraint and sensitivity to cues for hunger and satiety. Physiology and Behavior, 47, 477-481.

Ogden, J., \& Wardle, J. (1991). Cognitive and emotional responses to food. International Journal of Eating Disorders, 10, 297-311.

Polivy, J. (1976). Perception of calories and regulation of intake in restrained and unrestrained eaters. Addictive Behaviours, 1, 237-243.

Polivy, J., \& Herman, C. P. (1976a). Clinical depression and weight change: A complex relation. Journal of Abnormal Psychology, 85, 338-340.

Polivy, J., \& Herman, C. P. (1976b). Effects of alcohol on eating behaviour: Influence of mood and perceived intoxication. Journal of Abnormal Psychology, 85, 601-606.

Rodin, J. (1980). Externality theory. In A. J. Stunkard (Ed.), Obesity. Philadelphia: W.B. Saunders.

Ruderman, A. J. (1985). Dysphoric mood and overeating: A test of restraint theory's disinhibition hypothesis. Journal of Abnormal Psychology, 94, 78-85.

Schachter, S., \& Rodin, J. (1974). Obese humans and rats. Washington DC: Erlbaum/Haltsted.

Schoemaker, C. G., van Strien, T., \& van der Staak, C. P. F. (1994). Validation of the EDI in a non-clinical population using transformed and untransformed responses. International Journal of Eating Disorders, 15 , 387-393.

Slochower, J. A. (1983). Excessive eating: The role of emotions and environment. New York: Human Sciences Press, Inc.

Spencer, J. A., \& Fremouw, W. J. (1979). Binge eating as a function of restraint and weight classification. Journal of Abnormal Psychology, 8, 262-267.

Stunkard, A. J., \& Messick, S. (1985). The Three-Factor Eating Questionnaire to measure dietary restraint, disinhibition and hunger. Journal of Psychosomatic Research, 29, 71-83.

Van Strien, T. (1986). Eating behaviour, personality traits and body mass. Lisse: Swets \& Zeitlinger b.v.

Van Strien, T., Frijters, J. E., Bergers, G. P. A., \& Defares, P. B. (1986). The Dutch Eating Behaviour Questionnaire for assessment of restrained, emotional and external eating behaviour. International journal of Eating Disorders, 5, 295-315. 
Van Strien, T., Frijters, J. E. R., Van Staveren, W. A., Defares, P. B., \& Deurenberg, P. (1986). The predictive validity of the Dutch Restrained Eating Scale. International Journal of Eating Disorders, 5, 747-755.

Van Strien, T., Schippers, G. M., \& Cox, W. M. (in press). On the relationship between emotional and external eating behavior. Addictive Behaviors.

Wardle, J. (1987). Eating style: A validation study of the Dutch Eating Behaviour Questionnaire in normal subjects and women with eating disorders. Journal of Psychosomatic Research, 31, 161-169.

Wardle, J., \& Beales, S. (1987). Restraint and food intake: An experimental study of eating patterns in the laboratory and in everyday life. Behaviour Research and Therapy, 25, 179-185.

Wardle, J., \& Beinart, H. (1981). Binge eating: A theoretical review. British Journal of Clinical Psychology, 26, 47-56.

Wardle, J., Marsland, L., Sheikh, Y., Quinn, M., Fedoroff, I., \& Ogden, J. (1992). Eating style and eating behaviour in Adolescents. Appetite, 18, 167-183.

Westenhoefer, J. (1991). Dietary restraint and disinhibition: Is restraint a homogeneous construct? Appetite, 16, 45-55.

Woody, E. Z., Costanzo, P. R., Liefer, H., \& Conger, J. (1981). The effects of taste and caloric perceptions on the eating behaviour of restrained and unrestrained subjects. Cognitive Therapy and Research, 5, 381-390. 